\title{
LAS RELACIONES DE PODER Y LA DUALIDAD ENTRE FEMENINO Y MASCULINO EN"EN ESTE PUEBLO NO HAY NIÑOS"
}

\author{
THE RELATIONS OF POWER AND THE DUALITY BETWEEN \\ FEMININE AND MASCULINE IN “EN ESTE PUEBLO NO \\ HAY NIÑOS"
}

Thais Chaves Marinho'

\begin{abstract}
RESUMEN
Este estudio tiene como objetivo analizar las relaciones de poder construidas por el juego entre las voces narrativas femenina y masculina en el cuento "En este pueblo no hay niños", incluido en el libro Los relojes de Adela, de Gabriela Caballero Delgado, a partir de la teoría de la Microfísica del Poder, desarrollada por Michel Foucault (1998). Asimismo, el estudio se inserta en la perspectiva de género para discutir la escritura de autoría femenina, a partir de las teorías de Nelly Richard (1993 y 1996), Joan Scott (1990 y 2012) e Hilda Beatriz Garrido (2005). Este estudio, finalmente, pretende comprender la relación dual entre las voces femeninas y masculinas y cómo esa dualidad remite a la cultura andina.
\end{abstract}

Palabras claves: Género, literatura peruana, mujeres.

\begin{abstract}
The purpose of this research is to evaluate the relations of power built by the game played between the feminine and masculine narrative speeches within the tale "En este pueblo no hay niños", included in the book "Los relojes de Adela", by Gabriela Caballero Delgado, based on the theory of the Microphysics of power, developed by Michel Foucault (1998). Likewise, the research is related to the gender perspective to discuss the writing of feminine authorship writing, from the theories of Nelly Richard (1993 and 1996), Joan Scott (1990 and 2012) and Hilda Beatriz Garrido (2005). This study, finally, aims to understand the dual relation between the feminine and masculine speeches and how this duality sends us towards the Andean culture.
\end{abstract}

Key Words: Gender, peruvian literature, women.

\footnotetext{
${ }^{1}$ Universidade Federal de Minas Gerais. Belo Horizote- Brasil.E-mail: marinho.ta@gmail.com
} 


\section{INTRODUCCIÓN}

La literatura de autoría femenina, a pesar del creciente espacio que ocupa en la escena literaria, todavía presenta poca visibilidad. Algunos datos pueden ayudarnos a percibir cómo la literatura sigue siendo un campo dominado por la producción masculina, como lo demuestran los análisis cuantitativos que hace Regina Dalcastagnè sobre la producción literaria brasileña. Aunque no digan del escenario latinoamericano de una forma general o del escenario peruano específicamente, los datos nos permiten entrever un panorama que es común también en los países vecinos.

La investigación "Mapeamento de personagem do romance brasileiro: anos 1970, anos 1990", coordinada por Dalcastagnè y ejecutada en la Universidad de Brasilia entre 2004 y 2006, analizó 389 novelas brasileñas publicadas en los períodos de 1965 a 1979 y 1990 a 2004. En el primer período, se examinaron 131 obras de 87 escritores diferentes, 72 de los cuales eran hombres; es decir, un $82,8 \%$ de la totalidad. En el segundo período, se consideraron 258 novelas escritas por 165 autores diferentes: de este conjunto, 120 eran hombres, esto es $72,7 \%$. Según la teórica, en una relación organizada para un premio literario de 130 novelas brasileñas publicadas en 2004, 31 títulos fueron escritos por mujeres: lo que representaba un $23,8 \%$ del total (Dalcastagnè, 2010, p.240). A partir de esos datos es posible percibir que, si bien el número de mujeres escritoras en Brasil aumentó considerablemente en un corto espacio de tiempo, todavía la literatura de autoría femenina representa una parcela pequeña del total de escritores.

Por otro lado, las producciones académicas —que de alguna manera sí reflejan la sociedad en la cual están insertas y los temas que están en boga - también pueden traer informaciones interesantes sobre la producción de las mujeres. Cuando volvemos la mirada hacia el período entre 2013 y 2015, vemos un gran aumento de tesis y disertaciones que discutieron obras de autoras mujeres o temas relacionados con la producción femenina, en el Programa de Posgrado de la Facultad de Letras de la Universidad Federal de Minas Gerais (UFMG).

Según datos de la página web del Programa de Posgrado, en 2013, esos trabajos representaron un $5 \%$ de un total de 76 ; en 2014 ese número subió a 13\% de 63; y en 2015 de 64 investigaciones, $25 \%$ analizaron la autoría femenina o temáticas relacionadas. Sin embargo, a pesar del aumento significativo, la discusión académica sobre obras de mujeres o de temáticas caras a ellas aún es inferior respecto del total de investigaciones. En estas pocas cifras, se percibe que por lo general las obras de escritoras se utilizan para que los investigadores varones teoricen sobre la autoría femenina, la representatividad de mujeres y/o temas relacionados con ese universo - lo que sí es relevante- Sin embargo, los estudios de las obras de escritores se orientan a temas "universales", como el amor, la guerra, la memoria, etc. A partir de estas diferencias de enfoques se puede inferir que lo masculino sigue siendo aún hoy el patrón desde el cual los lectores miramos y reflexionamos sobre el mundo.

Hablar del espacio de la escritura de autoría femenina en el mercado editorial, así como de los estudios críticos y académicos acerca de autoras mujeres, es hablar de representatividad. Valorar e incentivar -que incluye consumir y estudiar esas obras- la producción de mujeres en la literatura implica propiciar la visibilidad y relevancia de los discursos y las experiencias de un grupo minoritario en sentido político. Dalcastagnè cita a Foucault: "en toda sociedad la producción de discursos es, al mismo tiempo, controlada, seleccionada y redistribuida por determinado número de procedimientos que tienen el papel de conjurar sus poderes y sus peligros" (cit. en Dalcastagnè, 2010, p. 43). El control del discurso sería, entonces, una censura social velada que silencia a los grupos dominados.

Así que es crucial reflexionar sobre la importancia de la crítica y del estudio de obras producidas por mujeres. Para discutir el papel de esa crítica feminista de arte, Katy Deepwell cita a Joanna Russ. Según Russ, ese campo de estudio "debe ofrecer modelos de la práctica artística de las mujeres al público, proporcionar contextos para la interpretación de las obras y lenguaje(s) o marcos teóricos para comunicar con iguales de cada cual" (Deepwell, 1998, p.27. Traducción mía). De esa manera, Deepwell (1998) apunta que la crítica de arte feminista sigue siendo una "crítica con causa", en tanto que su función sería constituir un desafío a la representación de las obras de las mujeres en una cultura 
que continúa devaluándola, denigrándola e ignorándola. El feminismo, como señala Deepwell (1998), es una herramienta que puede y debe ser usada por la crítica para poner en juego una serie de debates sobre lo que significa ser mujer(es) en una cultura patriarcal.

La teórica también plantea la pregunta: ¿qué hace, entonces, que la crítica sea feminista? Y contesta que el trabajo de poner los textos de mujeres y sobre mujeres en el foco, con la intención de informar al público, quizá incluso educarlo sobre las obras de mujeres o los logros feministas: "Al final su estrategia tal vez invierta críticamente la atención, eternamente privilegiada, que se dedica a los artistas varones y a los intereses masculinistas del mundo del arte, o al menos intervendrá en ellos" (Deepwell, 1998, p. 30-31).

Analizar la escritura de autoría femenina a partir de una crítica feminista es abrir espacio y destacar una voz que en general se ve relegada en una sociedad que todavía privilegia la mirada y el discurso masculinos.

Los relojes de Adela, de la escritora peruana Gabriela Caballero Delgado, que incluye el cuento "En este pueblo no hay niños" es muy significativo; por cuanto la autora está doblemente a las orillas de la producción cultural peruana. Gabriela Caballero Delgado es mujer en el Perú, y específicamente en Tacna, una ciudad pequeña en la frontera con Chile, lejos de los grandes centros culturales. Su producción literaria, que posee una gran calidad técnica, fue publicada por una editora independiente de la ciudad, creada por su pareja.

Ese estudio tiene como objetivo analizar las relaciones de poder construidas por el juego entre las voces narrativas femenina y masculina en el cuento "En este pueblo no hay niños". El texto narra la llegada de un profesor a una ciudad sin niños. Él desea construir una escuela, pero los hombres de la villa desconfian de sus intenciones. Su presencia cambia la historia local, así como la vida de los personajes. Con el profesor llega también la fertilidad de la tierra y de las mujeres, antes estériles. La vida, que estaba destinada a no seguir su ciclo en aquel pueblo sin niños, se renueva.

La narración se da a través de dos voces - una femenina y otra masculina - que se alternan y se mezclan. Las voces representan una colectividad y delinean imágenes de un femenino y de un masculino, además de dejar entrever relaciones de poder establecidas a lo largo del texto. $\mathrm{La}$ hipótesis de estudio es que la voz femenina, aparentemente sumisa, tensiona las relaciones de poder dominantes; asume el protagonismo de los actos, y define los rumbos de la historia.

El estudio de este relato de Caballero busca comprender las relaciones de poder que se construyen a partir de la teoría sobre el poder, aportada por Michel Foucault (1998). Además, ese estudio se inserta en una perspectiva de género $y$, para eso, buscaremos comprender la obra de la autora en el marco de las teorías que analizan la escritura de autoría femenina.

\section{DESENVOLVIMIENTO}

\section{Tradición y cosmovisión andina}

"En este pueblo no hay niños" se inserta en la tradición literaria peruana al rescatar la figura simbólica de la escuela. Dos grandes pilares de la literatura en el Perú trabajan de manera emblemática el tema. José María Arguedas - escritor, antropólogo y etnólogo - construye la narrativa de Los ríos profundos alrededor de la imagen de la escuela. La obra fue publicada en 1958 y narra la historia de Ernesto, un muchacho que conoce más de cerca las injusticias y contradicciones de la sociedad peruana al ser matriculado como interno en un colegio católico. La escuela por sí misma es un espacio violento que refleja la crueldad y los prejuicios del mundo externo. Entre los alumnos se ve la prevalencia de la ley del más fuerte y las relaciones entre ellos se basan en poses y prestigio social, donde lo que viene del mundo indígena es devaluado.

El segundo pilar es la obra La ciudad y los perros, de Mario Vargas Llosa. Primera novela del escritor peruano que posteriormente ganó el Premio Nobel de Literatura, la obra fue publicada en 1962. La historia también se centra en una escuela, pero en este caso una escuela militar, un ambiente marcado por la disciplina y por la violencia, y también un microcosmos de la sociedad peruana. Los personajes principales son Alberto Fernández, "el Poeta"; Ricardo Arana, "el Esclavo"; y El Jaguar. Muchachos que se ven obligados a encontrar ardides para sobrevivir en ese espacio. No hay villanos, tampoco héroes. Hay sobrevivientes de ese espacio opresor. 
El cuento de Gabriela Caballero Delgado gira asimismo alrededor de una escuela. Sin embargo, y curiosamente, esa es una escuela que no existe de hecho. Es solamente la idea, quizás podríamos decir: la amenaza de una escuela. La promesa de ese espacio llega por medio de un profesor, figura diferente de aquellas que comandan los espacios escolares de Los ríos profundos y La ciudad y los perros, respectivamente un padre y un militar. No se asocia inmediatamente el profesor, diferente de las otras dos figuras, a un orden opresivo e impositivo. Al revés, la imagen de un educador nos remite a la idea de un camino, de una salida por medio del conocimiento.

Sin embargo, ¿qué significa el profesor en esa sociedad transculturada, como es la sociedad peruana? El concepto, propuesto por el sociólogo cubano Fernando Ortiz (1940) y adoptado y trabajado desde la perspectiva literaria por Ángel Rama (1982), describe la influencia mutua y compleja resultado del contacto entre distintas culturas, especialmente en los casos en que una de esas culturas está subordinada o dominada por otra (Kokotovic, 2006, p. 17). En el pueblo del cuento de Gabriela Caballero Delgado, el profesor representa la "civilización" frente a ese espacio sin conocimientos formales y sin leyes. Como en las obras de Arguedas y Vargas Llosa, el espacio escolar de Caballero Delgado ya es la imposición de una visión de mundo, aunque de hecho no llegara a existir. ¿Qué escuela sería esa si la idea se hubiera concretizado?

En La modernidad andina en la narrativa peruana: conflicto social y transculturación (2006), Micha Kokotovic analiza las representaciones de las culturas indígenas de los Andes en algunos autores centrales peruanos, entre ellos Arguedas y Vargas Llosa, y señala que la modernización dependiente que se ha establecido en países latinoamericanos perpetúa una heterogeneidad cultural que proviene desde la conquista (Kokotovic, 2006, p. 24). El autor señala que todos los escritores enfrentan esa heterogeneidad y algunos han intentado representarla e incorporarla en sus obras. Kokotovic afirma incluso que la transculturación narrativa hace referencia a un proceso creativo a partir del cual, algunos escritores han intentado interpretar contradicciones y conflictos sociales de esa modernización dependiente en sus obras.
En la obra de Caballero Delgado se percibe esa heterogeneidad, principalmente referida a las huellas del mundo andino en el texto. La cosmovisión $^{2}$ andina se basa en algunos principios bases: complementariedad, relacionalidad, ayllu, reciprocidad, memoria oral colectiva, localismo y heterogeneidad (Orozco, 2011, p. 112).

La complementariedad está relacionada con la idea de que símbolos, imágenes y conceptos opuestos no se oponen; sino se complementan y juntos forman una unidad completa e integral. La relacionalidad, a su vez, dice de la totalidad y dependencia entre sí de las plantas, animales y del hombre. Y a la unidad socioeconómica andina, que incluye el grupo de personas ligadas por parentesco en un determinado territorio común, se nombra ayllu. A través de esos principios se puede percibir que para el mundo andino todo está relacionado y se complementa de forma interdependiente. Además de esos principios, otro punto importante en la cosmovisión andina es la organización del tiempo-espacio como señala Edith Orozco- de manera cíclica y continua, que busca siempre el origen:

El tiempo resulta ahistórico, pero dirigido a un futuro superior; utópico e ideal, pues para el quechua el futuro no es algo que viene y el pasado no es algo que se acumula atrás, más bien debe entenderse que es el quechua hablante el que en aquella circularidad del tiempo viene del futuro y el pasado que está allí. (Orozco, 2011,p. 122)

En el cuento "En este pueblo no hay niños", tiempo y espacio carecen de marcaciones territoriales que puedan ubicar al lector en una geografía concreta. Se sabe que es un pueblo aislado y rural, en un tiempo donde la ley es todavía demarcada por lo masculino y basada en la violencia. Aunque existe una antigua cárcel no hay un aparato institucional de justicia. $\mathrm{La}$ ley proviene de la voz masculina, que se interroga acerca del forastero que llega al pueblo y que decide matarlo cuando su

\footnotetext{
"Aquí es importante definir el término "cosmovisión" que, según el Centro de Culturas Originiarias Kawsay, se refiere a "la elaboración humana que recupera las maneras de ver, sentir y percibir la totalidad de la realidad, esto es, los seres humanos, el conjunto de la naturaleza y el cosmos". (Como se citó en Brun, 2009, p.84)
} 
presencia es demasiado incómoda. Los principios apuntados por Orozco también se reflejan en el cuento.

La unidad socioeconómica, el ayllu, se ve en esa comunidad, ligada por lazos de parentesco en ese pueblo sin niños. La llegada del profesor amenaza el ayllu y modifica la manera como la comunidad interactúa, así como el colonizador en siglos pasados. La relacionalidad también se hace presente una vez que la tierra, aquí representada por los conejos y las paltas, se muestra en una relación de contigüidad con esa comunidad y consecuentemente con los cambios que atraviesan. La complementariedad, a su vez, se refleja en la dualidad de las voces narrativas.

En la cultura andina, según Brun (2009, p.86), el hombre y la mujer andinos forjan una integralidad total y absoluta con plantas, bosques, animales, territorios, minerales, ríos, lagos, montañas, espacios celestiales y entornos estelares; lo que origina una integridad comunitaria holística interactiva y única. Sobre ese tema, Huanacuni, citado por Brun, menciona:

[En la cultura andina] existen dos fuerzas, la cósmica que viene del universo, del cielo (Pachakama o Pachatata); y la fuerza telúrica, de la tierra (Pachamama). Las dos energías generan toda forma de existencia, estas dos fuerzas convergentes están expresadas en todo proceso de la vida. $Y$ las diferentes formas de existencia se relacionan a través del Ayni (la complementariedad y la reciprocidad). (Como se citó en Brun, 2009, p. 86)

Pacha, término presente en las palabras pachamama y pachakama, de acuerdo al Centro de Culturas Originarias Kawsay, es la realidad cósmica integral: "En la Pacha se interarticula lo femenino con lo masculino: Khari: hombre y warmi: mujer. Pachamama es la energía negativa que es femenina, y pachakamak la energía positiva que es masculina, así como la relación entre la luna y el sol" (como se citó en Brun, 2009, p.84). La Pachamama o madre tierra es, de esa manera, una deidad femenina que representa el espíritu de la tierra. Además representa la maternidad y la fecundidad. Así, resulta ser a esa deidad a quien ruegan las mujeres. Al enterarse de que el profesor se marcha, le entregan sus cuerpos y le piden a la madre tierra que le dé a él los niños que tanto quiere. La madre tierra atiende los ruegos de las mujeres, volviéndolas fértiles. La tierra también refleja esa fertilidad: los conejos se multiplican y las paltas abundan en las ramadas desde la llegada del profesor (Caballero Delgado, 2009, p. 17).

Sara Guardia (2002) también señala la importancia de la relación dual para la cosmovisión andina. En Mujeres peruanas: el otro lado de la historia, ella destaca, citando a Osvaldo Silva: "La cosmovisión dual, 'es una forma de ver el mundo que implica entenderlo como compuesto por una multitud de parejas de opuestos. [...] se entiende que todo tiene dentro principios que luchan entre sí y que, a la vez, se complementan...' ", (como se citó en Guardia, 2002 , p. 22). Las voces femeninas y masculinas en "En este pueblo no hay niños" se insertan en ese universo dual. Son opuestas, sin embargo, se complementan formando un todo único. Solamente conocemos la integralidad de la historia narrada a través de la alternancia de las dos voces que, en esa mezcla y contraposición, se convierten en una sola voz narrativa. En el siguiente fragmento se percibe cómo las voces se alternan y se contraponen para construir la narrativa:

Cómo no íbamos a sentir pena por él al ver que trabajaba solo, limpiando de piedras el terreno elegido para la escuela de unos niños que no podíamos tener, junto a la canchita donde jugaban los hombres por las tardes, pero ni por eso lo ayudaron. Tuvimos que hacerlo nosotras a escondidas mientras se iban a la chacra. Y cuando volvíamos a la hora del almuerzo solo encontrábamos en los platos papas sancochadas y huevos duros. Entonces nos decían que todo el día estuvieron trepadas en la ramada. Escogiendo los higos malos. O desgranando los cholos amontonados en la cocina. Pero los higos estaban pudriéndose en la ramada y los choclos escondidos bajo las camas, bien al fondo para que ellos no pudieran descubrirlos en tanto acomodaban sus zapatos. (Caballero Delgado, 2009,p. 16) 
La narración conforma un círculo, la voz femenina empieza a contar la historia - "Esa mañana hallamos muerto al profesor y no pudimos derramar una sola lágrima por él. Las agotamos todas de tanto llorar cuando los hombres salieron a matarlo la noche anterior" (Caballero Delgado, 2009, p. 15) - y la termina - "Entonces nos llevamos su corazón y lo enterramos en el patio de la escuela que se llenaría con todos sus hijos" (Caballero Delgado, 2009, p. 20).

A lo largo del cuento, las dos voces se alternan, confundiéndose, creando un contrapunteo dual que refleja la complementariedad andina. Además, la narración juega con el tiempo, una vez que construye una narrativa no-lineal en la cual el texto se va adelante y hacia atrás, reforzando la idea de un tiempo cíclico. Para ejemplificar esa estrategia, nos referiremos al fragmento en que los hombres quieren expulsar al profesor, una vez que construyó la escuela y sigue con la idea "sin sentido" de permanecer en el pueblo, y las mujeres les impiden concretizar ese deseo, hablándoles "suavecito" sobre los niños que cargan en el vientre:

En el fondo, llenos de rabia pensando que las muy putas ni siquiera esperaron a terminar de construir la escuela. Un nudo nos creció en el pecho cuando él habló de lo inútil de sus esfuerzos y que iba a marcharse porque en este pueblo no teníamos niños. (Caballero Delgado, 2009, p. 20)

En ese momento, la voz narrativa femenina asume protagonismo y el tiempo narrativo vuelve hacia antes de que la escuela estuviese construida. No hay marcas lingüísticas que delimiten ese flashback. El cambio se da de manera fluida, como si esos diferentes tiempos hicieran parte de un solo todo cronológico.

\section{Escritura Femenina y Género}

Como este trabajo pretende discutir el cuento de Gabriela Caballero Delgado desde una perspectiva de género, es importante determinar algunas cuestiones introductorias como la existencia, o no, de una "escritura femenina"; además de precisar el concepto de género y de masculino y femenino.

El interés de la crítica literaria hacia al análisis de obras escritas por mujeres - y no limitarse a analizar la representación de la mujer en obras de autores masculinos - se inicia hacia 1975. Ese análisis de las escritoras como un grupo aparte se justifica, según Elaine Showalter (como se citó en Moi, 2006, p. 61), no porque las escritoras sean todas iguales o porque desarrollen un estilo parecido, propiamente femenino; sino porque cuentan con una historia específica. Esta historia incluye consideraciones complejas como la relación con el mercado literario, los espacios sociales y políticos de las mujeres en la sociedad y las implicaciones de los estereotipos de las escritoras, además de las restricciones a su independencia artística.

Para las autoras clásicas de esa línea de pensamiento, en la llamada crítica feminista angloamericana, tales como Elaine Showalter, Ellen Moers, Sandra Gilbert y Susan Gubar, es la sociedad y no la biología lo que construye y conforma la escritura propia de las mujeres (Moi, 2006, p. 63).

Nelly Richard (1993 y 1996) plantea la discusión de si tiene sexo la escritura, es decir, si existiría una escritura femenina. En su texto "Feminismo, experiencia y representación” (1996), apunta que la crítica feminista puso de manifiesto que “el lenguaje no es el vehículo impersonal -neutro y general - que postula la tradición masculina para defender la trascendente universalidad de su discurso maestro" (Richard, 1996, p. 739). De esa manera, según la investigadora, lo supuesto neutro de la lengua y su consecuente desinterés en las diferencias cumple la función de enmascarar el operativo de la universalización a la fuerza de lo masculino como representante absoluto del género humano.

En su texto, “¿Tiene sexo la escritura?” (1993), Nelly Richard afirma que decir que el lenguaje y la escritura son indiferentes al género/sexo refuerza el poder establecido, una vez que sigue encubriendo las técnicas mediante las cuales la masculinidad hegemónica disfraza con lo neutro la personalización de lo universal. Eso no significa, sin embargo, que "la escritura misma (como dispositivo significante) obedezca en su estructura a una clave monosexuada" (Richard, 1993, p. 131). 
Así, Richard apunta que, para una mujer, tomar la palabra es ingresar a un universo donde se legislan los discursos por reglas masculinas, teniendo como base un modelo de representación que devalúa lo femenino como categoría inferior y secundaria (1996, p. 740). Según la investigadora, "el lenguaje, la escritura literaria y las normas culturales llevan la huella de este operativo de forzamiento institucional que subordina los textos a paradigmas de apreciación y recepción dictados por una escala de valores sociomasculinos" (Richard, 1996, p. 740).

Partiendo de los conceptos de Kristeva, Richard afirma que independientemente de los condicionamientos biológicos-sexuales del autor, la escritura pone en movimiento el cruce interdialéctico de varias fuerzas de subjetivación y señala que dos de esas fuerzas son la semiótica-pulsional (femenina) y la racionalizante-conceptualizante (masculina). Las dos fuerzas actúan en los procesos de subjetivación creativa, es el predominio de una sobre la otra que polariza la escritura sea en términos masculinos, cuando se impone la norma estabilizante; 0 en términos femeninos, cuando hay un movimiento desestructurador.

La teórica afirma asimismo que el problema va más allá de ser una "escritura femenina" o no y del género del sujeto-autor biográfico. Tendríamos que hablar de una feminización de la escritura:

...feminización que se produce cada vez que una poética o que una erótica del signo rebalsan el marco de retención/contención de la significación masculina con sus excedentes rebeldes (cuerpo, libido, goce, heterogeneidad, multiplicidad, etc.) para desregular la tesis del discurso mayoritario. Cualquier literatura que se practique como disidencia de identidad respecto al formato reglamentario de la cultura masculino-paterna; cualquier escritura que se haga cómplice de la ritmicidad transgresora de lo femenino-pulsional, desplegaría el coeficiente minoritario y subversivo (contra dominante) de lo "femenino". (Richard, 1993, p. 132)
De esa manera, el sujeto biográfico no es un elemento esencial. "Ser mujer" no garantiza que habrá en la obra un ejercicio crítico que cuestiona los parámetros culturales dominantes, ni "ser hombre" condena al autor a ser partidario y reproducir las formas $y$ discursos del poder de la cultura oficial. Para Richard, la mujer sí establece una relación privilegiada con esa fuerza que ella llama lo somático-pulsional. Eso se justifica debido a que está situada en la frontera de la cultura donde ese control y esa sujeción son más vulnerables. Sin embargo, eso no garantiza la transgresión de la escritura. Ese concepto "rechaza la coincidencia natural entre determinante biológica (ser mujer) e identidad cultural (escribir como mujer) para explorar las brechas y descalces de representación que se produce entre la experiencia del género (lo femenino) y su puesta en escena enunciativa" (Richard, 1996, p. 741).

La escritura de Gabriela Caballero Delgado está inserta en ese lugar inestable: ese femenino que "toma la palabra" en un universo legislado por reglas y representaciones masculinas y se pronuncia en ese cruce de fuerzas. El cuento de Caballero Delgado juega con imágenes $\mathrm{y}$ símbolos de ese universo y los refleja; pero también los tensiona, desestructurando el discurso dominante mayoritario masculino, principalmente en lo que toca a las relaciones de poder entre las dos voces narrativas y a los temas de la sexualidad y del deseo femenino. La obra de Caballero Delgado hace parte de un contexto duplamente marginalizado de la literatura de autoría femenina, contexto a que Richard (1996) hace referencia, inferiorizada tanto por la centralidad del poder masculino cuanto por el poder de la metrópolis occidental. El juego entre las dos voces narrativas, femenina y masculina, que se mezclan y se alternan, representa bien la relación entre los bordes del habla señalados por Richard: el borde inferior (femenino) de lo psicosomático y el borde superior (masculino) de lo lógicoconceptual, no son rígidamente opuestos sino fronteras que se mueven de manera interdialéctica (Richard, 1996, p. 740). Así la escritura surgiría justamente de la contradicción entre esas dos fuerzas. 
Lucia Castello Branco, en $A$ mulher escrita, también busca desenredar los hilos de la trama de lo que sería la escritura femenina. La teórica señala que la escasa teoría desarrollada alrededor de esa discusión no esclarece el tema. Como Richard, define "escritura femenina" como una configuración discursiva específica, que puede ser entendida como femenina a partir de una serie de correlaciones; pero, producida tanto por hombres como por mujeres (Castello Branco, 1990, pp.12-13). Así, para Castello Branco, tampoco importa el sexo biológico. Lo importante es el análisis de la construcción del texto y cómo él conforma un trazado que se pueda llamar femenino.

Sin embargo, señala que el discurso femenino se expresa con mayor frecuencia y propiedad en el texto de mujeres. Además, lo que muchas veces se entiende por "femenino" se asemeja y se confunde con lo que se entiende por "ser mujer" y "eso se explica por el hecho de que, aunque los dos términos no sean sinónimos, y por eso no se puede intercambiarlos. Lo femenino es un concepto que se construye a partir de la idea de mujer como derivación (o característica) de mujer, o de hembra" (Castello Branco, 1990, pp.13-14. Traducción mía). Vemos de hecho que su definición de escritura femenina - presentada en un texto en que Castello Branco se permite poner a sí misma, acercarse a lo poético y alejarse del cartesiano y del logos, lógicas asociadas a lo masculino-se confunde y se funde a los conceptos e imágenes del "ser mujer" en nuestra sociedad.

Castello Branco, en su discurso, plantea la existencia de un lenguaje femenino que no se codifica según los moldes masculinos (Brandão y Castello Branco, 2004, p. 121). La teórica afirma que ese lenguaje femenino sería anterior a la Ley del Padre, concepto del psicoanálisis planteado por Jacques Lacan. Aquí es interesante hacer un breve paréntesis para explicar el concepto. En Teoría Literaria Feminista, Toril Moi pone en diálogo a Lacan con obras feministas (Moi, 2006) y explica que en la teoría lacaniana hay dos términos fundamentales: el Orden Simbólico y el Imaginario. Lo imaginario corresponde a un

\footnotetext{
${ }^{3}$ Escrito en co-autoría con Ruth Silviano Brandāo en 1989 y reeditado en 2004, y en su tesis de doctorado "A traição de Penélope: uma leitura da escrita feminina da memória", presentada en 1990.
}

periodo que sería pre-edípico, donde el niño no percibe ninguna separación entre él mismo y la madre, creyéndose parte de ella. De esa manera, no existe ausencia, solo identidad y presencia. Esa unidad se rompe con el padre y la imposición de una distancia entre madre e hijo.

A partir de la Ley del Padre, entonces, se impone la crisis edípica y se entra en el Orden Simbólico vinculado también a la adquisición del lenguaje. Así, el Falo, que está asociado a la Ley, significa separación, pérdida y carencia. El deseo de madre, o de unidad imaginaria con ella, debe ser reprimido; lo que Lacan llama de represión primaria, a partir de la cual se funda el subconsciente. De esa manera, entrar en el Orden Simbólico necesariamente es aceptar el Falo como ese elemento disociador y fragmentador. La cultura humana y la vida en sociedad están dominadas por el Orden Simbólico y tienen el Falo como símbolo de la carencia.

$\mathrm{Al}$ adentrarse en el Orden, el niño se distingue de un "tú" y de un "él". O sea, el sujeto construye su identidad a partir de la distinción de lo que no es y de la comparación con "el otro" a su alrededor. Así, según Moi (2006, p. 109), "hablar como sujeto es, por tanto, lo mismo que representar la existencia del deseo perdido: el sujeto hablante es carencia, y así es como Lacan puede decir que el sujeto es lo que no es". "El otro" es ese espacio de formación del sujeto. Como apunta Moi, es "la estructura diferencial del lenguaje y de las relaciones sociales que constituyen el sujeto en primer lugar y en el que (el sujeto) debe asumir su lugar" (Moi, 2006, p. 110).

A partir de esa explanación es posible comprender mejor lo que Castello Branco plantea sobre el lenguaje femenino que, siendo anterior a la Ley del Padre, se configuraría en un universo prediscursivo, "en el cual la voz, el cuerpo y el toque de la madre funcionen como significantes, imprimiendo un significado en contacto con el cuerpo del niño" (Brandão y Castello Branco, 2004, p. 122. Traducción mía). En ese sentido la escritura femenina deviene en un proyecto imposible, porque sería un registro verbal de un proceso a-verbal. Para la investigadora, lo que ella llama escritura femenina, por estar situado en un entre lugar donde el Orden Simbólico-y consecuentemente el Falo - no domina, resiste 
la mediación lingüística e intenta acercarse y pegarse al referente, buscando ir más allá del signo. La escritura femenina presentaría un carácter circular, el lenguaje se asoma sobre sí mismo. Más adelante en $A$ mulher escrita, la investigadora afirma que una manera menos agresiva de ver la escritura femenina sería “aquella que se encamina para lo imposible del discurso, por los silencios del innominable, por los absurdos de un pre lenguaje que se ve más allá del verbo, pero que se ve también como comunicación" (Brandão y Castello Branco, 2004,p. 145. Traducción mía).

En ese lenguaje, el cuerpo gana protagonismo y se pone en el discurso, en un registro que pretende ser oído y no exactamente leído. Béatrice Didier, citada por Castello Branco, afirma que "esa característica oralizante del texto femenino se funda en una práctica secular - la tradición oral - en que la mujer, sobre todo, la abuela, con sus historias y canciones de cuna ocupó papel determinante" (como se citó en Brandão y Castello Branco, 2004, p. 123. Traducción mía). Eso imprimiría al texto femenino características específicas, ritmo y tiempo, principalmente, que lo alejarían de la narrativa tradicional.

En el cuento de Caballero Delgado, "En este pueblo no hay niños", vemos un lenguaje que podríamos llamar oralizante, no porque el texto en sí presente características lingüísticas del lenguaje oral; sino por su estructura narrativa, donde las voces femenina y masculina, siempre en el plural, simbolizando un colectivo, se mezclan, se complementan, conformando un círculo. Es un discurso fragmentado, que se adelanta y vuelve hacia atrás en el tiempo. Lo fragmentario, lo no-lineal y lo colectivo son características también presentes en una narrativa oral.

Pero, lo que más acerca el texto de Caballero Delgado a lo dicho por Castello Branco es que ese femenino en el cuento se construye en aquello que no lo es, ante ese masculino que habla, que cuenta la historia y que, al principio, la domina. Ese femenino se delinea justamente en confrontación con esas reglas y con ese poder masculino; sus deseos y actitudes son en respuesta a ese otro, sean los hombres del pueblo, sea el forastero.
Se puede asociar esa voz femenina presente en el cuento con la voz femenina analizada por Castello Branco (1990, p. 125. Traducción mía), "una voz exiliada, descentrada, desfigurada, quizá, pero, tal vez, solamente en la radicalización de sus gestos [...] consiga que le escuchen y que la vean en su otredad. No el patrón unisex, sino la diferencia".

En ese diálogo con el psicoanálisis, Castello Branco demarca el lugar de lo femenino como ausencia:

Es en el vacío, en la ausencia, que se ubica y se construye el concepto de femenino [...]. Esa invisibilidad, que el psicoanálisis ha visto con cierta pasión y el pensamiento feminista ve con cierto recelo, no significa, sin embargo, inocuidad, inferioridad, inexistencia. (Castello Branco, 1990, p. 127. Traducción mía)

Más allá de la relación con las teorías psicoanalíticas, hay una discusión que es histórica y cultural. Si los lugares de producción del discurso - las ciencias, la historia, los espacios de poder, la propia literatura - fueron por un largo tiempo masculinos, lo femenino se construye como el "otro", ante ese que es el patrón: lo masculino. La máxima de Simone de Beauvoir todavía es actual, lo femenino sigue siendo el "segundo sexo": "La representación del mundo, así como el mundo mismo, es operación de los hombres; ellos lo describen a partir del punto de vista que conocen y que se confunde con la verdad absoluta" (Beauvoir, como se citó en Duarte, 2002, p. 28. Traducción mía).

Las herramientas para la definición de lo femenino están dadas a partir de la mirada masculina. Bajo las reglas ya establecidas y en comparación con ese otro masculino, se delimita lo femenino. En ese sentido, Moi (2006, p. 77) apunta que el pensamiento machista trae sus propios criterios de lo que considera valores "positivos", teniendo como indicadores fundamentales el Falo y el Logos. Así, todo lo que se asocie a los "llamados valores 'positivos' del Falo se considera bueno, auténtico, bello; cualquier cosa que no esté construida de acuerdo con el modelo del Falo se considera caótico, fragmentado, negativo o inexistente"(Moi, 2006, p. 77). 
Al desarmar el concepto de género como biológico (como veremos con profundidad más adelante) y trabajarlo como un concepto socialmente construido, se busca afirmar que se podrían asociar tales características con mujeres u hombres. Sin embargo, la lógica de buscar que esas características valoradas sean también asociadas a lo femenino, sigue devaluando las características señaladas como femeninas, lo que mantiene la lógica masculinista.

En esa compleja imbricación, el sujeto femenino se construye necesariamente contradictorio, fragmentado y multifacetado - por lo menos en ese momento histórico-. En el cuento también se ve lo femenino como contradictorio y multifacetado. En un primer momento, es presentado como pasivo ante los hombres, acepta los roles que le son dados. Pero, rápidamente, ese femenino se vuelve complejo. Su deseo y su voluntad ganan más espacio. No existe culpa o remordimiento ante el deseo que crece y el uso de artimañas y de mentiras, es decir, ante el quiebre de expectativas sobre ese femenino. Tampoco hay acciones que busquen revertir totalmente la situación. Hay una resignación y una aceptación de esos papeles del "ser mujer". Las mujeres manipulan el deseo de los hombres, pero no piensan en liberarse. Ellos siguen siendo "nuestros hombres".

También es interesante notar que la maternidad no se ve de una manera idealizada, ya que se la desea para que el profesor se quede. Otro punto importante que demuestra la complejidad de la figura femenina en el texto es el hecho de que todo el cuento gira alrededor de la figura masculina. Ese otro masculino continúa siendo central para definir lo femenino, es en comparación y alrededor de él que el femenino se delimita, se construye y se moviliza.

Volviendo al texto de Castello Branco, la teórica rescata a Ana María Portugal, autora que propone una metáfora del encaje para pensar lo femenino, relacionándola con el psicoanálisis lacaniano. Lo femenino sería, entonces:

Un lugar de vacío, pero de un vacío estructurante, bordeado por líneas que componen dibujos que, a su vez, componen otros vacíos [...] además de presentar una configuración de lo femenino, [esa imagen] nos sugiere aún el boceto de una posible poética de la feminidad, que, entonces se construiría a partir de brechas, de ausencias, de lapsos de memoria, de fragmentos. (Castello Branco, 1990, p. 131. Traducción mía)

La escritura de Caballero Delgado es también un bordado que crea un entramado complejo e intrincado, que es circular y que dibuja imágenes de un femenino y de un masculino. Al fin, se cuenta la historia de las mujeres, cuya voz narrativa empieza y cierra el texto. Aunque haya momentos en los que destaca el punto de vista de los hombres, lo relevante es la historia de las mujeres, su protagonismo, sus deseos y subversiones. Lo femenino es, finalmente, el personaje central de la trama, y el trazo de sus múltiples facetas va bordando el texto.

A partir de los aportes de Castello Branco y de Nelly Richard se ve un entrecruzamiento complejo de teorías. Están en juego aportes del psicoanálisis y de teorías feministas, muchas veces discordantes. Aquí está en discusión, si existiría una esencia de lo femenino, un "ser mujer" que se dejaría entrever en la escritura. Pero, "ser mujer" podría peligrosamente caer en la idea de que esa esencia sería condicionada por la biología.

Aunque Castello Branco afirme que la definición de escritura femenina que propone no está relacionada con el sujeto biológico "mujer", la acerca a las imágenes de un femenino muchas veces idealizado, que se aproxima al concepto de feminismo "esencialista" que Richard discute en el texto "Feminismo, experiencia y representación" (1996). La teórica apunta que esa corriente pone en el centro de la discusión la experiencia como fuente de una verdad primordial y la autenticidad sobre lo femenino. Esa valorización de la experiencia tiene la intención de invertir el sistema conceptual de la lógica masculina, de lo razonante que reprimió lo sensible, lo físico, lo afectivo y lo intuitivo: características asociadas a lo femenino. Ese feminismo antidesconstructivo sostiene que hay algo pre discursivo que relaciona cuerpo, experiencia y verdad.

Es un hecho que esa autoridad letrada masculina metropolitana, para no olvidarnos aquí del componente de la Colonia versus Metrópolis, se ha impuesto sobre los cuerpos y la oralidad 
femeninas. Sin embargo, Richard (1996, p. 737) señala que "orden, razón y signo" no se oponen de manera dual y aislada a "des-orden, cuerpo, rito y símbolo", sino "son registros culturales que se superponen y se mezclan localmente gracias a fuerzas transpositivas de desplazamiento y reabsorción de parte de los signos de la modernidad". Richard (1996, p. 739) alerta aún para el peligro de idealizar ese femenino al relacionarlo a algo anterior, auténtico y pre discursivo; lo que podría llegar a confirmar el estereotipo de una "otredad" romantizada. Eso, en lugar de invertir el orden machista, refuerza la jerarquía que valora y pone en el centro lo masculino $y$, a partir de esa valoración, hegemoniza las herramientas y conceptos del "pensar".

Con lo dicho hasta ahora ya tocamos la discusión de género. Sin embargo, como el eje central de este trabajo es el análisis de un femenino y de un masculino que interactúan dejando entrever relaciones de poder que reflejan nuestra sociedad más allá de la fícción del cuento, es primordial echar la mirada de forma más detallada hacia ese concepto.

Volviendo a Richard, para la teórica, lo masculino y lo femenino son fuerzas relacionales que interactúan como partes de un sistema de identidad y poder que las conjuga de forma tensional:

Lo femenino es la voz paradigmáticamente reprimida por la dominante de identidad que sobrecodifica lo social en clave patriarcal, pero liberar esa voz no implica substraerla del campo de tensiones que la enfrenta políticamente a lo masculino para aislarla en un sistema aparte que vuelve a excluir lo diverso y heterológico. (Richard, 1996,p. 741)

De esa manera, lo femenino podría designar ese vector de descentramiento que cuestiona la representación sexual y cultural, y que además reflexiona sobre "las maniobras expresivas que utiliza el discurso hegemónico para disimular el contrato masculino que legitima su apropiación de la cultura" (Richard, 1996, p. 743). Ese "femenino" operaría, según Richard, como un vector de cuestionamiento a los operadores culturales que naturalizan todo un régimen de significación.

En la visión que Teresita de Barbieri desarrolla en "Sobre la categoría género. Una introducción teórico-metodológica" (1993), los sistemas de género son:

...los conjuntos de prácticas, símbolos, representaciones, normas y valores sociales que las sociedades elaboran a partir de la diferencia sexual anátomo-fisiológica y que dan sentido a la satisfacción de los impulsos sexuales, a la reproducción de la especie humana $y$ en general al relacionamiento entre las personas. En términos durkheimianos, son las tramas de relaciones sociales que determinan las relaciones de los seres humanos en tanto personas sexuadas. (Barbieri, 1993,p.149)

Más adelante, la investigadora apunta que el género es una forma de la desigualdad social y de la jerarquía, que está articulado con otras formas de la desigualdad y de las jerarquías sociales (Barbieri, 1993, p.161).

Joan Scott, a su vez, en el artículo "Gênero: uma categoria útil de análise histórica" (1990) hace un recorrido por aspectos históricos y conceptuales de los usos del término con el objetivo de señalar la importancia de ese concepto para la investigación histórica. Afirma que las feministas americanas usaron el término "género" con el fin de enfatizar el carácter social de las distinciones basadas en el sexo. Según Scott (1990, p. 72. Traducción mía), "la palabra indicaba un rechazo del determinismo biológico implícito en el uso de términos como 'sexo' o 'diferencia sexual'. El término 'género' enfatizaba el aspecto relacional de las definiciones normativas de la feminidad".

Así, el término es usado para referirse a las relaciones sociales entre los sexos. Su uso rechaza explicaciones biológicas y busca indicar construcciones culturales, esto es, la creación social de ideas sobre los roles femeninos y masculinos. De esa manera, de acuerdo con Scott, género es una categoría social impuesta sobre un cuerpo sexuado. El término incluye, entonces, todo un sistema de relaciones que puede incluir sexo; pero no es determinado necesaria y directamente por él, ni 
determina directamente la sexualidad. En el texto escrito en 2012, "Os usos e abusos do gênero", Scott vuelve al tema y señala:

Género es la lente de percepción a través de la cual nosotros enseñamos los significados de varón/hembra, masculino/femenino. Un "análisis de género" constituye nuestro compromiso crítico con estos significados y nuestro intento de revelar sus contradicciones e inestabilidades y cómo se manifiestan en las vidas de aquellos que estudiamos. (Scott, 2012, p. 332. Traducción propia)

Posteriormente, el término "género" pasa a ser usado como sinónimo de mujeres. La investigadora afirma que ese uso del concepto constituye uno de los aspectos que marcan la búsqueda de legitimidad académica de los estudios feministas de los años 80 (1990, p. 75). Señala aún que, además de un sustituto para el término mujeres, "la palabra 'género' también se utiliza para sugerir que cualquier información sobre mujeres es necesariamente información sobre varones [...]. Esa utilización enfatiza el hecho de que el mundo de las mujeres forma parte del mundo de los hombres, que se crea en ese y por ese mundo masculino" (Scott, 1990, p. 75. Traducción mía).

En el artículo escrito en la década de 90, Scott critica la tendencia de poner como dimensión central del género, el antagonismo entre hombres y mujeres, y señala que "aunque la forma por la cual el 'sujeto' se construye permanezca abierta, la teoría propende a universalizar las categorías y las relaciones entre masculino y femenino" (Scott, 1990, p. 83. Traducción mía). Scott apunta que esa visión trae una idea a-histórica, esencialista del "ser mujer": "Cuando se insiste siempre en las diferencias fijadas [...], las/los feministas refuerzan el tipo de pensamiento que desean combatir. Aunque insistan en la reevaluación de la categoría 'femenino' [...], ellas no reexaminan la posición binaria" (Scott, 1990, p. 84. Traducción mía). De esa forma, propone que se analice la operación binaria, revirtiendo y desplazando la construcción jerárquica, al revés de naturalizarla.
En el texto escrito en 2012, su crítica es más dura. Scott apunta que, a lo largo de las décadas, los movimientos feministas formularon una identidad común a las mujeres basados en lo que llama "fundamentalismo biológico"; aunque la búsqueda haya sido por desesencializar $\mathrm{y}$ particularizar la experiencia de las mujeres.

Si en el texto de la década de 2000, Scott hace un balance de los usos - y abusos, como el propio título lo indica - del término género, en el artículo de la década de 90 , su preocupación se concentraba en demostrar la importancia del término y en conceptualizarlo. Así, presenta su definición de género en base a las siguientes proposiciones: "(1) el género es un elemento constitutivo de relaciones sociales basadas en las diferencias percibidas entre los sexos y (2) el género es una forma primaria de significar las relaciones de poder" (Scott, 1990, p. 86. Traducción mía). A partir de la primera proposición, enumera cuatro elementos interrelacionados que el género implica, enseñándonos cómo el género constituye las relaciones sociales e institucionales: primero, símbolos culturalmente disponibles que evocan representaciones simbólicas referentes al género; en segundo lugar, conceptos normativos expresos en doctrinas religiosas, educativas, científicas, entre otras, que intentan limitar y orientar la lectura metafórica de los símbolos; en tercer lugar, el ámbito político y social que extrapola el ambiente familiar y que conforma y es conformado por el género; $y$, por último, la identidad subjetiva del individuo, es decir, cómo hombres y mujeres construyen sus identidades subjetivas a partir de concepciones sociales y subjetivas de género.

En seguida, Scott desarrolla lo que sería el centro de su teorización acerca del género, afirmando que el concepto es un campo primario; aunque no sea el único, en el interior del cual, o por medio del cual, el poder es articulado (Scott, 1990,p. 88). La investigadora señala que el género es un conjunto objetivo de referencias, que estructuran la percepción y la organización concreta y simbólica de la vida en sociedad. Según Scott, como esas referencias establecen distribuciones de poder, una vez que posibilitan el control o acceso a recursos materiales y simbólicos, el género se vuelve parte de la concepción y de la construcción del poder (Scott, 1990, p. 89). 
Judith Butler, a su vez, propone una nueva - $y$, podemos decir, revolucionaria - manera de mirar al concepto de género, a partir de Problemas de gênero: feminismo e subversão da identidade (1990). La teoría feminista, como vimos anteriormente, construyó como pilar la dicotomía entre sexo y género. El sexo sería algo biológico, por lo tanto, natural; y el género, una construcción social. Butler (2003, p. 26) hace cuestionamientos en su obra con relación al carácter social de la construcción del género: ¿cuáles serían los mecanismos de esa construcción?, ¿la construcción del género podría ser diferente o hay una forma de determinismo social que excluye la posibilidad de transformación o de actuar del sujeto? Al final de las preguntas que plantea, afirma que la idea de construcción de género muchas veces sugiere un cierto determinismo, en que los significados relativos al género son vistos como inscritos en cuerpos que se diferencian anatómicamente, cuerpos que son vistos como pasivos de lo que ella llama ley cultural inexorable.

Cuando la "cultura" relevante que "construye" el género es comprendida en los términos de esa ley o conjunto de leyes, se tiene la impresión de que el género es tan determinante y tan fijo cuanto en la formulación de que biología es destino. En ese caso, no la biología, sino la cultura se vuelve destino.(Butler, 2003, p. 26. Traducción propia)

La investigadora señala, de esa manera, que aceptar el sexo como algo natural y el género como construido culturalmente sería asociar el género con una esencia del sujeto. Ella aún llama la atención para el vínculo entre género y deseo, visto muchas veces incluso por la teoría feminista, como natural.

Para Butler, a diferencia de las teorías feministas, el género se trataría de un fenómeno inconstante y relacionado al contexto. Y propone que el género sea visto como una relación entre sujetos socialmente constituidos, en contextos específicos. Así, "el género no denota un ser sustantivo, sino un punto relativo de convergencia entre conjuntos específicos de relaciones cultural e históricamente convergentes"(Butler, 2003, p. 29).

\section{Relaciones de poder en el juego narrativo}

Las primeras nociones de poder estaban relacionadas a la habilidad de imponer la voluntad de uno sobre otros. Así, se veía el poder como algo poseído por alguien que lo detenta y que lo usa para obtener ventajas y beneficios propios:

La definición de Hobbes, tal como se lee en el principio del capítulo décimo de Leviatã es la siguiente: "El Poder de un hombre... consiste en los medios de alcanzar alguna aparente ventaja futura". No es diferente, por ejemplo, de lo que Gumplowicz afirmó sobre la esencia del Poder: "consiste en la posesión de los medios de satisfacer las necesidades humanas $\mathrm{y}$ en las posibilidades de disponer libremente de tales medios". En definiciones como esas, se comprende el Poder como algo que se posee: como un objeto o una sustancia -observó alguien - que se guarda en un recipiente. (Bobbio et al. 1998, p. 933. Traducción mía)

Michel Foucault, a partir de su teoría de la "Microfísica del Poder", hace una inversión importante para los estudios del tema. El teórico ve el poder como relacional:

El poder no existe. Es decir: la idea de que existe, en un determinado lugar, $o$ emanando de un determinado lugar, o emanando de un determinado punto, algo que es un poder. En verdad, el poder es un haz de relaciones, más o menos organizado, más o menos piramidalizado, más o menos coordenado. (Foucault, 1998, p. 248. Traducción propia)

En su análisis, propone una mirada histórica hacia el concepto e identifica tres formas de poder, insertas históricamente en el tiempo. El poder soberano, estrictamente relacionado al vínculo de sangre y a la soberanía, se caracteriza por la amenaza de muerte, el "dejar vivir" y "poder matar". A su vez, el poder disciplinar se refiere al control sobre los cuerpos de los individuos, es "una tecnología de poder que trata el cuerpo del hombre como una máquina, 
objetivando adiestrarlo para convertirlo en un instrumento útil a los intereses económicos" (Diniz et al. 2014, p. 144. Traducción mía). El poder disciplinar $\mathrm{y}$, concomitantemente, el biopoder surgen en las sociedades europeas del siglo XVIII. De acuerdo con Diniz et al. (2014, p. 144), esas nuevas tecnologías de poder serían posibles con el adviento de la categoría "sujeto"; las cuales fueron el primer espacio en que se ejerció una nueva forma de poder. Según el autor, "esto ocurre con la institucionalización de las escuelas, de los hospitales, de los cuarteles, de las prisiones entre otros ambientes denominados como instituciones de 'secuestro'. Se utiliza esta denominación por el hecho de individualizar el sujeto y usar técnicas disciplinares para docilizarlo" (Diniz et al. 2014,p. 144. Traducción propia).

En oposición al poder disciplinar, en el biopoder el foco no es el cuerpo individualizado, sino el cuerpo colectivo. Diferente del poder soberano que, a su vez, "dejaba vivir", el biopoder "deja morir", ya que es "un poder que se encarga de la preservación de la vida, eliminando todo aquello que amenaza la preservación y el bienestar del pueblo" (Diniz et al. 2014, p. 144. Traducción mía).

En la genealogía del poder de Foucault, se ve como sobresaliente la idea de que el poder no es algo natural, sino una práctica social, construida históricamente. De esa manera, el poder no lo posee alguien y tampoco está localizado en un punto específico de la estructura social. Es una red de dispositivos y mecanismos a que nada o nadie escapa. Washington Luis Souza, que en su texto "Ensaio sobre a noçâo de poder em Michel Foucault" (2011) hace un recorrido por la visión foucaultiana sobre el poder, afirma que "no se puede pensar [el poder] a partir de una idea de posesión, sino a partir de la noción de ejercicio o funcionamiento. La relación establecida por los polos ejercicio o lucha, de un lado, y resistencia, de otro, es más apropiado" (Souza, 2011, p. 103. Traducción mía).

La perspectiva foucaultiana desplaza el foco del Estado y analiza el poder a partir de las extremidades. De esa manera, el Estado pasa a ser visto ya no como el órgano central y único del poder. El poder pasa, así, a ser entendido como una red que no posee límites, ni bordes; en la cual todos están insertos, lo que significa que él no está concentrado en ningún punto específico de esa red.

Otra característica importante del poder, según la teoría foucaultiana, es que la dominación no es la esencia del poder. Aunque diversos grupos estén imbricados en esa telaraña del poder, conformando relaciones jerárquicas $y$ desiguales, ningún grupo posee el control de las relaciones establecidas.

La discusión planteada por Foucault aparece en el cuento "En este pueblo no hay niños". Dos voces en plural, que representan respectivamente la mirada femenina y la masculina, cuentan la misma historia, alternándose, mezclándose como en un contrapunteo. En muchos momentos no se nota cuál de las voces es la que está manifestándose. La transición entre una y otra es sutil e intencionalmente ambigua. Vemos abajo un ejemplo que demuestra la alternancia y mezcla de las voces:

Esta mañana hallamos muerto al profesor y no pudimos derramar una sola lágrima por él. Las agotamos todas de tanto llorar cuando los hombres salieron a matarlo la noche anterior. La primera vez que lo vimos, a todos nos extrañó su presencia. E s t u vi m os si g u i n d o disimuladamente sus pasos como si no nos importase. Como si ni siquiera hubiésemos visto que llegaba. Luego nos fuimos acercando con ellas enredándose en nuestras camisas. Lo rodeamos. Le preguntamos quién era. Qué venía a buscar aquí. Después nos reímos, ¿profesor?, pero ¿de quiénes? Si en este pueblo no hay niños, dijeron nuestras mujeres removiendo la tierra con sus pies desnudos. Ensuciándonos por detrás los zapatos. Sin embargo, estaba aquí, sosteniendo aquella mochila en el hombro y nos fuimos dejando jalar por los hombres que continuaron riéndose (...). (Caballero Delgado, 2009, pp. 15 y 16)

Las primeras dos frases nos señalan que quien empieza la narración es la voz femenina y enuncia que no pudieron derramar una sola lágrima por la muerte del profesor, pues las agotaron cuando los hombres salieron a matarlo 
en la noche anterior. A partir de la tercera frase no hay marcas lingüísticas que nos aseguren quién es el narrador. En la sexta frase, sin embargo, percibimos que la voz narrativa es la masculina, ya que son los hombres quienes se acercan al profesor con las mujeres junto a ellos. Entre las dos primeras frases, en las cuales se ven marcas de que la voz narrativa es femenina, y la sexta, en que se intuye la voz masculina, no está claro cuál voz asume la narración. Esta lógica de alternancia y mezcla se mantiene a lo largo del cuento.

Desde ese juego narrativo podemos entrever relaciones de poder que circulan por el texto. Inicialmente, la voz femenina se presenta como sumisa y hay claramente una relación de poder desigual. En la cita anterior se ve que las mujeres se acercan al profesor junto a los hombres, "enredándose" en sus camisas. Ellas remueven la tierra con los pies desnudos, ensuciando a los hombres, que están calzados. Al fin, las mujeres se van, dejándose jalar por los hombres, que ríen.

A lo largo de todo el texto otros indicios dan cuenta de esa relación de poder que aunque no se dice de forma clara, sin embargo se puede notar en los detalles de forma explícita. Es importante resaltar que esa relación entre lo femenino y lo masculino no solamente permea el cuento; sino que es la base del texto, siendo lo interesante de la trama justamente el tensionamiento entre lo masculino y lo femenino.

En ese sentido, el género sería un elemento clave en esa noción relacional del poder. Como ya se ha apuntado anteriormente, para Joan Scott el género es el primer modo de significar las relaciones de poder, puesto que el género es:

... un primer campo en el seno del cual o por medio del cual, se articula el poder. El género no es el único campo, pero parece haberse constituido como un medio persistente y recurrente de dar eficacia a la significación de poder en el Occidente, en las tradiciones judaico-cristianas e islámicas. [...] El género es así un medio de codificar el sentido y de comprender las relaciones complejas entre diversas formas de interacción humana. (Scott, 1990, p. 88)
Hilda Beatriz Garrido en su texto "Identidades de género. Prácticas y significaciones” (2005) también afirma que el género es un elemento constitutivo de las relaciones sociales basadas en las diferencias jerárquicas que se perciben entre los sexos y es una manera primaria de relaciones significantes de poder. De acuerdo con Garrido: "A partir de este concepto, los roles desempeñados por varones y mujeres están signados por los modelos de comportamiento sexual impuestos por la sociedad y por la forma en que esa sociedad ha estructurado sus esquemas de poder" (Garrido, 2005, p. 51).

Las relaciones de poder, por lo tanto, están inmersas, permean y -podríamos decirfundan las relaciones de género. Utilizar la teoría de Foucault para mirar las temáticas relacionadas a género es interesante porque revoluciona la manera con que antes se veía la cuestión del poder en el feminismo. Bajo esa visión, como lo explican Costa et al. (2012, p. 229), el poder no lo posee el hombre o el Estado, de manera irrevocable e inmutable, sino que el poder es una telaraña en el cotidiano - y nadie está destituido de él- es lo que plantea el concepto de "Microfísica del Poder". De esa manera, las mujeres sí poseen mecanismos de poder dentro de esas relaciones y esos mecanismos están relacionados a la capacidad de resistencia de los sujetos.

Para Foucault, todo poder es ejercicio y genera resistencia, lo que significa que puede ser contestado, aceptado y absorbido (Costa et al, 2012, p. 235). Así, según Queiroz, citada por Costa:

... la resistencia, o mejor, la multiplicidad de puntos de resistencia sería inherente al ejercicio de poder [...] jamás podemos ser enteramente aprisionados(as) por el poder [...] hay siempre la posibilidad de modificar su dominación en condiciones determinadas y segundo en estrategias precisas. (Como se citó en Costa et al, 2012,p. 235. Traducción mía)

Se nota la resistencia en la voz narrativa femenina del cuento "En este pueblo no hay niños" $y$, a su vez, cómo esa resistencia significa un tensionamiento en la relación entre lo masculino y lo femenino. Las mujeres utilizan 
el engaño, omitiendo a los hombres la ayuda que dan al profesor: "Tuvimos que hacerlo [ayudar al profesor a limpiar el terreno de la escuela] nosotras a escondidas mientras se iban a la chacra [...]. Entonces nos decían [a los hombres] que todo el día estuvieron trepadas en la ramada. Escogiendo los higos malos [...]. Pero los higos estaban pudriéndose en la ramada" (Caballero Delgado, 2009, p.16). Los hombres les prohíben darle comida al profesor; pero las mujeres deciden, también a escondidas, llevarle el almuerzo (Caballero Delgado, 2009, p.17).

Además, el cuerpo y la seducción femenina son espacios de resistencia en la relación de poder establecida. Por ejemplo, luego de que el profesor termina la escuela, los hombres van a su encuentro "reírse de él y de su trabajo sin sentido [...]. Pero él continuó sentado en el patio de su escuela, mirándonos en silencio. Quisimos golpearle allí mismo" (Caballero Delgado, 2009, p.17). En ese momento, la voz narrativa cambia, asumiéndola las mujeres: "Y nos acercamos a sus oídos, hablándoles suavecito, convenciéndolos de que le permitieran quedarse porque la escuela estaría llena con los niños que ya nos crecían en el vientre" (Caballero Delgado, 2009, pp.17-18). De esa manera, la seducción y el engaño son armas. Ellas llevan a los hombres a casa, les dan aguardiente, buscando convencerlos de que los hijos son suyos y que permitan que el profesor se quede. Más adelante, las mujeres usan directamente sus cuerpos como forma de tensionar la relación de poder e inclinar la balanza en favor de su voluntad:

Supimos que moriría al oírlos murmurando borrachos en la cocina [...] $\mathrm{Y}$ evitamos su muerte [del profesor] por seis días y seis noches ciñéndonos a sus cuerpos. Se desnudaban frente a nuestros ojos [a los ojos de los hombres]. Se tendían a nuestro lado. Nos acariciaban la espalda. Mordían nuestros hombros. Pero no pudieron retenernos más... (Caballero Delgado, 2009, p. 19)

Los cuerpos, así, son también armas de convencimiento y de contorneo de la voluntad de otra figura masculina en el cuento: las mujeres usan el cuerpo para que el profesor se quede, como ellas desean. Es perceptible, además, un afloramiento $-\mathrm{y}$, tal vez podamos decir, una toma de control- de la sexualidad femenina con la llegada del profesor: "Luego no pudimos contener toda la fiebre anidándose en nuestro vientre. Nos consumimos en los ardores de nuestra piel" (Caballero Delgado, 2009, p. 18). Ese despertar de la sexualidad y asumir un mayor control sobre sus cuerpos y deseos también puede ser visto como una forma de resistenciay, consecuentemente, de poder.

Aline Troian (2013, p. 73) afirma que "las relaciones de poder influencian los comportamientos y las expresiones en lo que se refiere a la sexualidad, de tal modo que es posible decir que la forma como vivimos nuestras identidades sexuales es mediada por los significados culturales sobre la sexualidad que se producen por medio de sistemas dominantes de representación". De ese modo, la manera como el cuerpo y la sexualidad de la mujer son vistos en el cuento es reflejo de la cultura patriarcal en que están insertados y de las relaciones de poder establecidas. De ese modo, no es sorprendente que el cuerpo femenino sea utilizado como parte integrante del juego en esas relaciones de poder.

En el texto "O corpo e a reprodução da feminidade: uma apropriação feminista de Foucault", Susan Bordo (1997) trabaja la importancia del cuerpo en cuanto un agente de la cultura y un lugar práctico de control social, principalmente cuando analizamos las relaciones de poder y de género. Según la teórica, el cuerpo es poderosa forma simbólica, superficie en la cual las normas centrales, las jerarquías y los comprometimientos de una cultura están inscritos (Bordo, 1997, p. 19).

En su análisis, Bordo echa mano de las teorías foucaultianas acerca de los cuerpos y señala cómo los cuerpos son, a través de la organización del tiempo, de los espacios y de los movimientos de nuestra vida cotidiana, entrenados y marcados por las formas históricas de individualidad, deseo, masculinidad $\mathrm{y}$ feminidad (Bordo, 1997, p. 20). Así, los cuerpos dóciles, concepto aportado por Foucault, serían esos cuyas fuerzas y energías estarían habituadas al control externo, a la sujeción y a la transformación.

Si los cuerpos son lugares prácticos de control social y espacios en los cuales se inscriben 
formas simbólicas sociales, los cuerpos, específicamente los femeninos, son reflejo de las relaciones de poder que se establecen entre los géneros en la sociedad.

Barbieri (1993) señala que el cuerpo femenino, por tener la capacidad de crear otro cuerpo, es valioso socialmente $\mathrm{y}$, por eso, pasible de control. Para asegurarse un control efectivo sobre la reproducción, sin embargo, es necesario actuar también sobre la sexualidad, "puesto que [...], controlar la reproducción de manera que el o los varones puedan reclamar derechos sobre el producto específico de las mujeres, requiere de reglamentar el acceso al cuerpo femenino" (Barbieri, 1993,p. 152).

En el cuento de Caballero, los hombres buscan el control no solamente del cuerpo femenino, sino de sus deseos y de lo que elijan. En ese sentido, es interesante percibir que solo cuando las mujeres asumen el control sobre sus cuerpos y sexualidad, recuperan la capacidad de procrear.

Recordando a la teoría de Foucault y a la idea de que donde existe poder, existe resistencia, Barbieri afirma:

...las/los dominadas/os tienen un campo de posibilidades de readecuación, obediencia aparente, pero desobediencia real, resistencia, manipulación de la subordinación. De ahí entonces que los lugares de control sobre las mujeres -en nuestras sociedades el desempeño de los papeles de las madres-esposas-amas de casa- sean también espacios de poder de las mujeres: el reproductivo, el acceso al cuerpo y la seducción, la organización de la vida doméstica (Torres Arias, 1989). Se vuelven entonces espacios contradictorios, inseguros, siempre en tensión. (Barbieri, 1993, p.160)

En el cuento las mujeres ejercen la resistencia, y consecuentemente el poder, en espacios que conciernen muchas veces a lo doméstico, como señala Barbieri. Estos espacios se relacionan con los roles de madres y esposas, es decir, con el cuidado a alguien y con reproducción. La seducción, a su vez, es otra cara de la misma moneda, que tiene que ver con el juego del cuerpo femenino como herramienta de poder.
Así, a pesar de su aparente sumisión, los personajes femeninos van tomando control de los rumbos de la historia y adquiriendo protagonismo. Ellas ayudan al forastero en contra de la voluntad de los hombres y cuando el profesor les habla de lo inútil de sus esfuerzos y que iba a marcharse de allí, ellas le ofrecen sus cuerpos, conjurando a la tierra para darle los niños que pedía y así él "no se alejara nunca de nosotras" (Caballero Delgado, 2009, p. 18). Luego cuando ven que la muerte del profesor ya es inevitable, la dirigen ellas mismas "para librarlo de la ira de nuestros hombres" (Caballero Delgado, 2009, p.20):

...ya no podíamos procurarle otro día. El rencor de ellos se habría acrecentado aún más. $Y$ después de bañar su cuerpo con agua de belladona y adormecerlo con la infusión de la raíz del beleño y el aroma de los floripondios ocultos en su cama, cortamos su pecho para librarlo de la ira de nuestros hombres. Entonces nos llevamos su corazón y lo enterramos en el patio de la escuela que se llenaría con todos sus hijos. (Caballero Delgado, 2009, p. 20)

De esa manera, las voces femeninas tensionan las relaciones de poder establecidas, por medio de esas micro resistencias, una vez que contornean el deseo de los hombres, modificando las fronteras que delimitan el poder masculino e imponen que su deseo guíe de manera predominante los acontecimientos.

\section{CONCLUSIONES}

En el cuento "En este pueblo no hay niños", incluido en el libro Los relojes de Adela, de Gabriela Caballero Delgado, podemos establecer relaciones entre el concepto de género e imágenes relacionados a lo femenino y a lo masculino construidos histórica y socialmente. Este trabajo buscó explorar tales conexiones, relacionándolas a discusiones sobre el poder, especialmente al concepto de "Microfísica del Poder" (1998), aportado por Michel Foucault. Además, se intentó situar la obra de Caballero Delgado en el contexto literario y social peruano, estableciendo relaciones con obras pilares de la literatura del 
Perú, además de analizar las posibles huellas del mundo andino en el cuento.

Los debates sobre "escritura femenina" abarcan un largo campo teórico y se relacionan fuertemente con la noción de género y con las imágenes trazadas sobre lo femenino. Al entrar en ese universo teórico se vuelve difícil no tomar en cuenta las teorías feministas. De la misma manera, reflexionar desde el psicoanálisis enriquece este debate.

Esas discusiones son productivas para analizar, más allá de la ficción, cómo esas temáticas traspasan lo social y nos penetran. El texto de Caballero Delgado es relevante también en ese sentido, por las imágenes relativas al género que dibuja en el entramado del cuento y por la construcción de las relaciones de poder que deja entrever. Así mismo por ser un texto producido por una escritora mujer en una región que se podría ver como periférica en términos de producción cultural. Es decir, una obra que se vuelve representativa de voces muchas veces silenciadas.

\section{REFERENCIAS BIBLIOGRÁFICAS}

Barbieri, T. (1993) Sobre la categoría género: una introducción teóricometodológica. Revista Debates en Sociología, 18, 145-169. $\mathrm{R}$ e c u p e r a d o d e : http://revistas.pucp.edu.pe/index .php/debatesensociologia/article /view/6680

Bobbio, N., Matteucci, N. y Pasquino, G. (1998) Dicionário de política I. [Carmen C. Varriale, trad.] (3.a ed.). Brasília: Editora Universidade de Brasília. (Obra original publicada en 1909).

Bordo, S. (1997) O corpo e a reprodução da feminidade: uma apropriação feminista de Foucault. En A. Jaggar, S. Bordo. Autores (eds.), Gênero, corpo e conhecimento (pp. 19-41). Rio de Janeiro, Record: Rosa dos tempos.

Brandão, R. S., Castello Branco, L. (2004) A mulher escrita. ( $2^{a}$ ed.) Rio de Janeiro: Lamparina Editora.

Brun, H. Acercamiento a la visión cósmica del mundo andino. Punto Cero,
Cochabamba, v.14, n. 18 , p. 8389, 2009. Disponible en $<$ http://www.scielo.org.bo/pdf/r $\mathrm{pc} / \mathrm{v} 14 \mathrm{n} 18 / \mathrm{v} 14 \mathrm{n} 18 \mathrm{a} 10 . \mathrm{pdf}>$. Consulta en 09 oct. 2016.

Butler, J. (2003) Problemas de gênero: feminismo e subversão da identidade. [Renato Aguiar, trad.] Rio de Janeiro: Civilização Brasileira.

Caballero Delgado, G. (2009) Los relojes de Adela. Tacna: Cuadernos del Sur.

Castello Branco, L. (1990) A traição de Penélope: uma leitura da escrita feminina da memoria del programa de Literatura Comparada de la Facultad de Letras. (Tesis de doctorado, Universidade Federal de Minas Gerais) Recuperada de: http://www.bibliotecadigital.uf mg.br/dspace/handle/1843/BUB D-9D9GBU

Costa, R. G., Madeira, M. Z.A. y Silveira, C. M. H. (Noviembre, 2012) Relações de gênero e poder: tecendo caminhos para a desconstrução da subordinação feminina. En $17^{\circ}$ Encontro nacional da rede feminista e norte e nordeste de estudos e pesquisa sobre a mulher e relações de gênero, Encuentro llevado a cabo en João Pessoa, Brasil. Recuperada de: http://www.ufpb.br/evento/lti/oc s/index.php/17redor/17redor/pa per/view/56

Dalcastagné, R. (2010) Representações restritas: A mulher no romance brasileiro contemporâneo. En R. Dalcastagné, V. M. V. Leal. Autores (eds.), Deslocamentos de gênero na narrativa brasileira contemporânea. Vinhedo, SP: Editora Horizonte.

Deepwell, K. (1998) Crítica feminista de arte en un nuevo contexto. En K. Deepwell. Autora (ed.), Nueva crítica feminista de arte: Estrategias críticas (pp.19-39). Madrid: Ediciones Cátedra. 
Diniz, F. R. A., Oliveira, A. A. (Noviembre, 2013/Junio, 2014) Foucault: do poder disciplinar ao biopoder. Revista. Scientia, 2 (3), 143-157. R e c u p e r a d a d e : http://www.faculdade.flucianofe ijao.com.br/site_novo/scientia/s ervico/pdfs/VOL2_N3/FRANCI SCOROMULOALVESDINIZ.p df

Duarte, E. A. (2002) Feminismo e desconstrução: anotações para um possível percurso. En C. L. Duarte, E. A. Duarte, K. C. Bezerra. Autores (eds.), Gêneroe representação: teoria, história e crítica. Belo Horizonte: Pósgraduação em Letras Estudos Literários, Faculdade de Letras/UFMG.

Foucault, M. (1998) Microfisica del poder (13 ${ }^{\mathrm{a}}$ ed.) Rio de Janeiro: Edições Graal.

Garrido, H. B. (2005) Identidades de género. Prácticas y significaciones. En $\mathrm{S}$. B. Guardia (Editora). Escritura de la Historia de las Mujeres en América Latina. El retorno de las diosas. Lima: Centro de Estudios La Mujer en la Historia de América Latina; Editorial Minerva. Recuperada de: http://www.bdigital.unal.edu.co/ 45315/1/9972926443.pdf

Guardia, S. B. (2002) Mujeres peruanas: el otro lado de la historia. Lima: Editorial Minerva.

Kokotovic, M. (2006) La modernidad andina en la narrativa Peruana: conflicto social y transculturación. [José Ruiz, trad.] Berkeley: Centro de Estudios Literarios 'Antonio Cornejo Polar': Latinoamericana Editores.

Moi, T. (2006) Teoría Literaria Feminista. (4 ${ }^{\mathrm{a}}$ ed.) [Amaia Bárcena, trad.] Madrid: Cátedra.

Orozco, E. P. (2011) Racionalidades en conflicto: cosmovisión andina $(y$ violencia política) en Rosa Cuchillo de Óscar Colchado.
Lima: Pakarina.

Richard, N. (Marzo, 1993) ¿Tiene sexo la escritura? Revista Debate feminista, 9, 127-139. R e c u p e r a d a d e : https://www.jstor.org/stable/426 24218?seq=1\#page_scan_tab_c ontents

Richard, N. (Julio/diciembre, 1996) Feminismo, Experiencia y representación. Revista Iberoamericana, 62(176/177), 733-744. Recuperada de: h t t p s : / / r e vis t a iberoamericana.pitt.edu/ojs/inde x.php/Iberoamericana/article/vie wFile/6256/6432

Scott, J. W. (Julio/diciembre, 1990) Gênero: uma categoria útil de análise histórica. Revista Educação \& Realidade, 16(2), 5-22. $\mathrm{R}$ e c u p e r a d a d e : https://edisciplinas.usp.br/plugin file.php $/ 185058 / \mathrm{mod}$ resource/c ontent $/ 2 / \mathrm{G} \% \mathrm{C} 3 \% \mathrm{AAnero-}$ Joan\%20Scott.pdf

Scott, J. W. (2012) Os usos e abusos do gênero. Revista Projeto história, 45, $\mathrm{R}$ e c u p e r a d a d e : http://revistas.pucsp.br/index.ph $\mathrm{p} /$ article/view/15018/

Souza, W. L. (2011) Ensaio sobre a noção de poder em Michel Foucault. Revista Múltiplas Leituras, 4(2), 103-124. Reecuperada de https://www.metodista.br/revista

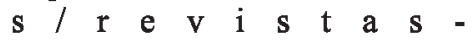
metodista/index.php/ML/article/ view/3160

Troian, A. D. (2013) Identidade feminina $e$ história em Arráncame la vida e Mal de amores del Programa de Pós-Graduação em Letras, Cultura e Regionalidade (Tesis de maestría. Universidade de Caxias do Sul) Recuperada de: https://repositorio.ucs.br/jspui/h andle/11338/758 